\title{
Reallocating Australia's Scarce Mental Health Resources
}

\author{
Ruth F.G. Williams and D.P. Doessel ${ }^{1}$
}

\section{Abstract}

This paper applies some simple analytical tools from the economists' toolbox to shed some light on a sleeper issue in Australia's mental health sector. The problem is that there are large numbers of people with no diagnosed mental health condition who consume mental health services. Simultaneously, there are large numbers of people who have very serious mental health problems who receive no mental health services. This untreated group is often referred to as those with 'unmet need', a much-heard term. We refer to the first group as people with 'met non-need', a term hardly ever heard. Although the solution to the unmet-need problem is the oft-heard call for increased government expenditure, no attention is directed to the wasted expenditure associated with the 'met non-need' group: the met non-need issue is 'the elephant in the room'. We point to an alternative policy response; that is, a reallocation of resources from the met non-need group to the unmet need group. To achieve this, we direct focus upon a structural reform in the processes of supplying mental health services.

\footnotetext{
$1 \quad$ La Trobe University, Ruth.Williams@latrobe.edu.au; formerly of the University of Queensland. This paper is an abridged version of a longer paper, available from the authors on request. The authors gratefully acknowledge the helpful comments of the editor and a referee on the original manuscript.
} 


\section{Introduction}

The purpose of this paper is to describe a long-standing problem in the provision of mental health services in Australia, ${ }^{2}$ and to outline a reform that addresses this problem. By way of background, we describe first some 'big picture' financial data that put the health sector, and various components of health expenditure, into a relative, and economic, perspective. The time-period is the 22 years from 1993-94 to 2013-14, the years for which we have comparable and reliable data. The background section highlights two differences that exist between mental health and non-mental health services in Australia. First, government now funds approximately 96 per cent of mental health expenditure, compared to a government share of 66 per cent of non-mental health expenditure. The second major difference between these two parts of the health sector relates to diagnostic information to guide therapy, also referred to as treatment: time-series government expenditure data on diagnostic imaging and pathology services indicate the quantitative importance of diagnostic information to medical therapies. But this expenditure is associated with nonmental health services: the Medicare Benefits Schedule is devoid of item numbers for any diagnostic test applying the numerous psychological tests that exist for schizophrenia, depression, suicidality, narcissistic personality disorder, and so on.

The paper then considers an empirical 'puzzle' that exists in Australia's mental health sector. This problem, which we refer to as 'structural imbalance', has two dimensions: first, some people with mental disorders do not consume mental health services, and, at the same time, some people who do not have a diagnosis of a mental disorder do consume mental health services. The evidence that this problem exists is not based on anecdote or adherence to a particular psychological or psychiatric theory: its existence is based on empirical evidence from carefully conducted, population-based epidemiological surveys.

The paper concludes with an argument that the structural imbalance problem is connected to the non-use of the large range of psychological tests for diagnosing mental disorders. A necessary reform is to insert diagnostic item numbers in the Medicare Benefits Schedule for psychological tests for mental disorders,

\footnotetext{
2 There is an early analysis of problems in the provision of mental health services in Australia by Opit and Gadiel (1982). The empirical data reported there demonstrated a number of problems in the provision of private fee-for-service psychiatric services: first, although the number of such services was increasing through time, the number of patients receiving them was not; and that those services were concentrated upon an 'elite' socioeconomic group. Unfortunately, these authors' further work on mental health issues was abruptly terminated. With their 1982 paper, all research on the economics of mental health care in Australia ceased until a substantive book was published in 2001 (Williams and Doessel 2001).
} 
and make positive results from these tests a prerequisite to accessing mental health services. Such a structural reform will enable a shift in resources to people who currently have unmet need.

\section{Background}

Australia's mental health expenditures (funded by Commonwealth, state and territory governments, as well as private sources) were $\$ 8,011$ million in 2013-14: in the same year total health expenditures were $\$ 154,622$ million. ${ }^{3}$ These amounts are not trivial: measured value-added in the health sector constitutes 9.8 per cent of GDP; mental health 0.51 per cent of GDP. Further, mental health expenditure, as a component of total health expenditure, has been steadily rising, from 4.87 per cent in 1992-93 to 5.18 per cent in 2013-14 (see the lowest line graph in Figure 1). This upward trend did not happen by chance. It was a deliberate act of whole-of-government decision-making.

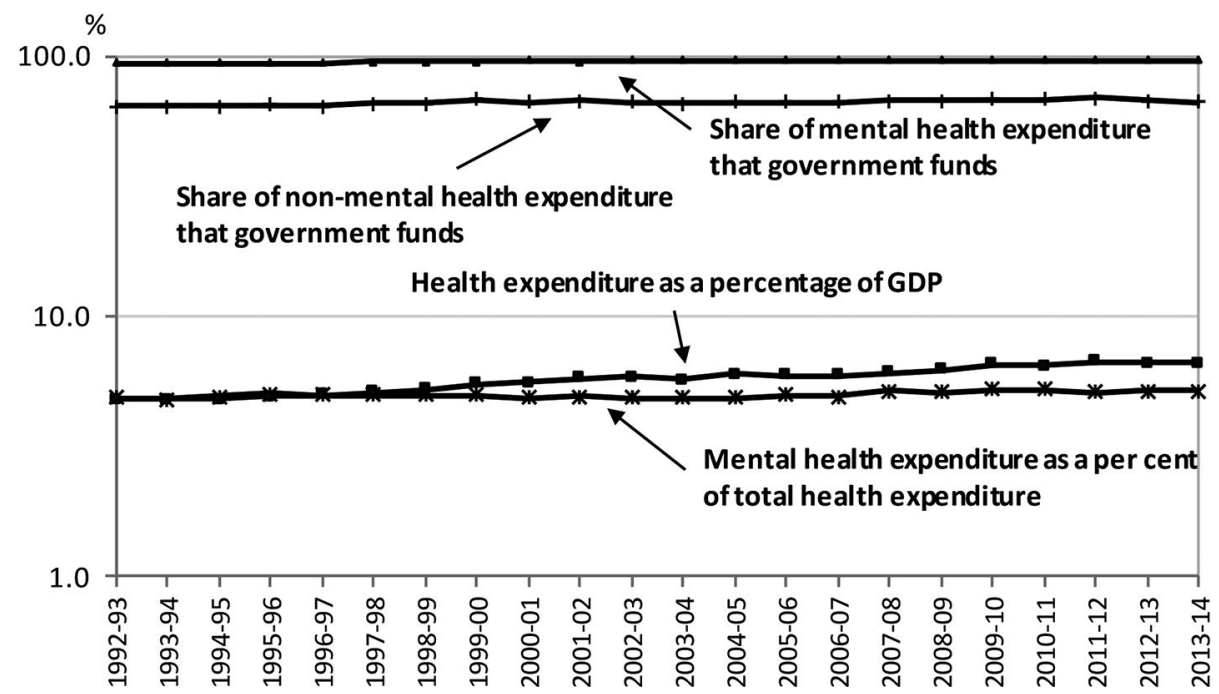

Figure 1: Relative sizes of four components of health expenditure, Australia, 1992-93 to 2013-14

Sources: AlHW (2016), Tables A1 and A4 (downloaded 29 June 2016); AlHW (2015), Table EXP31 (downloaded 29 June 2016).

3 Financial values herein are in constant 2013-14 prices. 'Expenditure' in this paper means 'Recurrent Expenditure', i.e. exclusive of capital. 'Government' means Commonwealth, state and territory governments. 
Figure 1 also shows the relative size of the health sector compared to the total economy, as measured by GDP: recurrent health expenditure in 1992-93 represented 7.31 per cent of GDP, and was 9.76 per cent in 2013-14. Over this 22-year period, health expenditure increased at a real compound annual growth rate (CAGR) of 3.2 per cent. The mental health sector has increased in relative size compared to the health sector, increasing from 4.87 per cent at the beginning of the period to 5.18 per cent in 2013-14.

Consider the two line graphs at the top of Figure 1: both describe shares of government expenditure on components of health - non-mental health expenditure and mental health expenditure. In 1992-93, government funded 64.3 per cent of non-mental health expenditure, and this had risen to 66.25 per cent in 2013-14. During this period, the CAGR for this component of health expenditure was 4.7 per cent. The highest line graph in Figure 1 describes the government-funded share of mental health expenditure. At the beginning of the period, the government share was 93.5 per cent; and in 2013-14, 96.1 per cent. During this period, the CAGR for mental health expenditure was 5 per cent, the highest growth rate of any economic data set considered in this paper.

These summary statistics indicate that expenditure on mental health services is growing at a faster rate than non-mental health services, as is the growth rate for government-funded mental health expenditure. But what is most notable about mental health expenditure is the abnormally high level of government expenditure: the lowest percentage share was just under 94 per cent in 1992-93, and the government share was over 96 per cent at the end of that period. These percentage shares are in stark contrast to those of non-mental health services. Thus, in funding terms, the mental health sector is different.

The mental health sector is also different in another respect, which one may illuminate via the three line graphs in Figure 2. These graphs are the Medicare benefits paid - that is, the Commonwealth Government subsidies - for two major categories of services: diagnostic imaging ${ }^{4}$ and pathology. ${ }^{5}$ All Medicare services are shown with a third line graph, where the $\mathrm{x}$-axis depicts the 31 -year period from 1984-85 for which consistent Medicare data are available. It is relevant to conceive of diagnostic imaging and pathology as those categories of services provided by specialists who, on referral, provide diagnostic information to other

\footnotetext{
4 Diagnostic imaging is exclusive of all radiology and any services that are therapeutic in nature, such as radiotherapy for cancer.

5 The 'bible' for Australia's Medicare system, the Medicare Benefits Schedule, as administered by the Commonwealth Department of Health, is constantly being revised (Medicare Australia, various). At the time of writing, the current version available online is The 1st November 2016 Medicare Benefits Schedule. This publication lists all services (with item numbers, descriptors, schedule fees, etc.) for which a Medicare benefit is payable.
} 
medical service providers about patients' medical conditions. It is noteworthy that the expenditure for these two 'Broad Categories of Service' (a term used in the Medicare Benefits Schedule) involves sizeable amounts. Diagnostic imaging and pathology totalled $\$ 1,601$ million in 1984-85 and \$5,714 million in 2014-15.

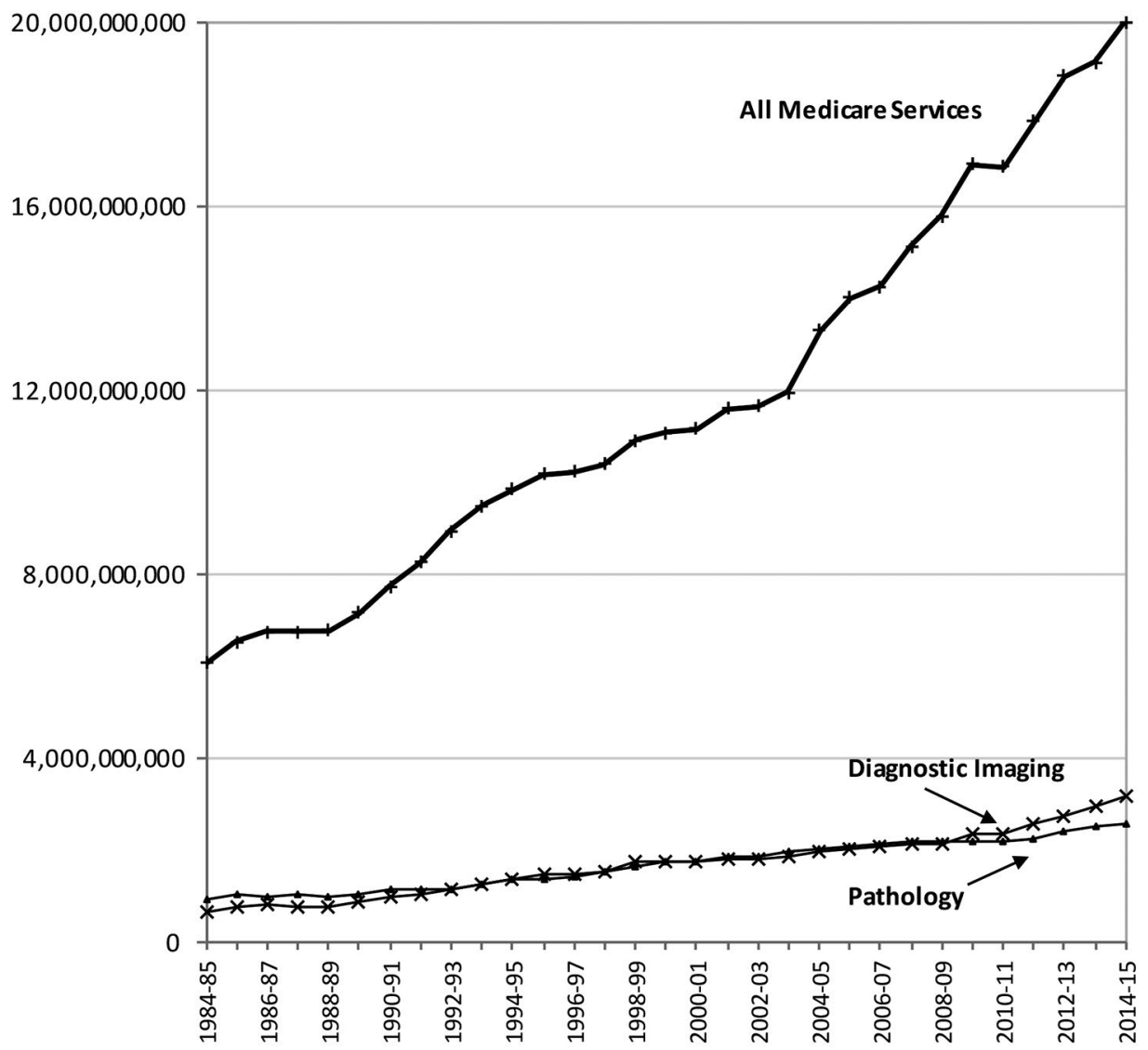

Figure 2: Benefits paid for Medicare services: pathology, diagnostic imaging and all services (dollars, constant 2013-14 prices, Australia)

Source: Australian Government Department of Health Medicare Statistics Table 2; available at: health. gov.au/internet/main/publishing.nst/Content/Medicare+Statistics-1

The data on which Figure 2 are based enable a particular calculation: expenditure on a variable that we will call 'All Medicare Services minus diagnostic imaging and pathology' or 'therapeutic services'. This variable is an (approximate) measure of all therapeutic services funded under Medicare. It is of interest here as data on this variable enable us to measure the relative importance of All Diagnostic Services (the sum of diagnostic imaging and pathology) to All Therapeutic Services, once expenditure on Therapeutic Services, as defined above, has been totalled. We have calculated that in 1992-93, expenditure 
on All Diagnostic Services represented 35.76 per cent of expenditure on Therapeutic Services in that year: in 2013-14 this percentage had risen to 39.15 per cent. ${ }^{6}$ In other words, for every dollar of expenditure on Therapeutic Services (as calculated here), approximately \$0.36-\$0.39 of expenditure was undertaken for the purpose of informing and guiding the provision of these therapeutic services.

We stress the role of diagnostic services because we wish to show another dimension in which the mental health sector is different: in Australia under Medicare, the financing of diagnostic services is confined to services of a nonmental health kind. There are no items for the performance of any diagnostic test for any mental disorder in Australia. ${ }^{7}$ And this is not because diagnostic tests are unavailable. A host of psychological tests exists, which can be administered, typically by qualified psychologists, for a host of mental disorders and illnesses, to determine whether a person has a mental illness; say, schizophrenia, depression, and so on. But there is no financial reward or incentive or structure for any such diagnostic testing that is parallel to the subsidising under Medicare of diagnostic testing for physical conditions. For such a step to occur under Medicare, the determination of schedule fees would be involved, and items would need to be published in the Medicare Benefits Schedule for mental health diagnostic tests.

Various mental health reforms have been undertaken in recent decades, as various scandals have shaken Australia's mental health system. ${ }^{8}$

Periodic scandals, of a human rights kind, have continued to characterise mental health, many of which were detailed in the Burdekin Report (HREOC 1993). There is a pattern to this societal process: there is a scandal following every new policy strategy, and a public inquiry follows, which in turn leads to further reform, calls for increased mental health services and expenditures, and another cycle starts. ${ }^{9}$

\footnotetext{
6 These calculations underestimate the information component of the health sector as they take no account of the initial 'screening'-type decisions of medical practitioners, sorting and storing patient records, etc. For early arguments about measuring the information economy and empirical results, see Machlup (1962), Porat (1977) and, more recently, Apte and Nath (2007).

7 Examination of the code numbers for these diagnostic services in the Medicare Benefits Schedule confirms this to be so; and in Figure 2, there is no line graph that depicts diagnosis of mental illness under Medicare. No line is there because nothing can be graphed.

8 Examples include the case between 1962 and 1979 of 'deep sleep therapy' at the (private) Chelmsford Hospital in Sydney, and the 'therapeutic community' scandal in Ward 10B at the Townsville General Hospital, which led a Royal Commission and a Commission of Inquiry, respectively.

9 See, for example, Hosking (2010); Mental Health Australia (2015); Hickie (2016).
} 
But by far the most significant factor was the process of deinstitutionalisation that took place in government-owned and operated long-term hospitals for the mentally ill. In a relatively short period of time, the number of such beds for the mentally ill across Australia fell from approximately 30,000 in the early 1960s to about 7,000 in 1992 (National Health Strategy 1993). ${ }^{10}$

This process did not occur as a result of miracle cures or 'silver bullets' for mental illness, or because mental illness had mysteriously ceased to strike members of the Australian community: it occurred as a result of deliberate public policy decisions by Australia's state governments. It should be recognised that these policy decisions reflected the conventional wisdom of the time, and took place (at much the same time) in other comparable countries (the United States, the United Kingdom, Canada, New Zealand, and so on) as well as in other sectors of health and welfare such as institutions for the physically and intellectually handicapped.

Deinstitutionalisation involved transferring the mentally ill to Australia's streets and, later, prisons, as the so-called community-based facilities and services were inadequate. Recognition of this collateral damage led to a number of major initiatives in the provision of mental health services.

A first response was the National Mental Health Strategy, which was, in large part, concerned with attitudes, behaviour, facilities and data collections in the public sector. (In fact, some data employed in this paper have been collected as a result of the Strategy.) The Strategy was processed by the existing intergovernmental arrangements involving both central and state and territory governments (Whiteford 1994; Whiteford and Buckingham 2005). At the time of writing (November 2016), this process was repeated in a series of five-year plans, the fourth of which concluded in 2013-14. The fifth iteration has been delayed, following a change in central government.

In addition to the implementation of this long-run policy with its five-year plans, there were a number of important ad hoc developments. Beyond Blue, established in 2000, was one of the first such. Another report (Mental Health Council of Australia 2005) documented many continuing deficiencies in the provision of mental health services. This report received widespread publicity and induced a political reaction. The following year, the (then) Prime Minister, John Howard, used the Council of Australian Governments (COAG) processes to open Medicare to psychologists, social workers, and so on. Subsequently, under

10 For a detailed empirical discussion of deinstitutionalisation, see Doessel (2009). 
the Gillard Government greater attention was given to adolescent matters ${ }^{11}-$ and another advisory organisation, the National Mental Health Commission, was set up.

Since the reforms began in the early 1990s the level of mental health expenditures has risen, from $\$ 2,815$ million in $1992-93$ to $\$ 8,011$ million by 2013-14; a compound annual growth rate of 4.9 per cent. By contrast, recurrent expenditure on all health services rose from $\$ 57,843$ million to $\$ 154,622$ million; a compound annual growth rate of 4.6 per cent. In that same period, GDP grew at a compound rate of 3.2 per cent. In fact, the relative size of the health sector has risen from 4.8 per cent of GDP in 1992-93 to 9.8 per cent in 2013-14. It should be noted that this period has been one of relative stability for health funding arrangements: the broad parameters of health funding have been constant since the introduction of Medicare in 1984. Note also that these data are based on a narrowly drawn definition of the health industry devised by Abel-Smith (1963) for the World Health Organization. More recently, the National Mental Health Commission (2015: 10) has implemented a 'wider' measure of Commonwealth responsibilities, taking into account the Disability Support Pension, Carer Payments and Allowances, and so on.

This article proposes that there are two parts of a single economic problem in mental health systems, a problem that we have named 'structural imbalance' (Doessel et al. 2008; Doessel et al. 2010; Williams and Doessel 2012). If some concepts from the literature on fiscal federalism are applied, the problem can also be conceived of as a case of imperfect correspondence (Oates 1972). In the next section, we elaborate on the structural imbalance and imperfect correspondence.

\section{The underlying economic problem: Concepts and evidence}

In general reference to all societies, the following statements are indubitable: vegetarians do not buy meat for their own consumption; people who do not own cars do not buy petrol; and so forth. Such statements cannot be made in the context of mental health. Some people with no clinical mental illness consume mental health services; and simultaneously some other people who have clinical manifestations of mental illness do not consume mental health services for various reasons. The term that can be applied to these two conjoint problems is structural imbalance. Structural imbalance can be delineated clearly: the concept

11 For example, the expansion of Headspace centres, following McGorry's 'solution' (McGorry et al. 1996). 
and its measurement are grasped when 'need' and service utilisation are crossclassified (Doessel et al. 2008). The notion of 'neediness' simply implies clinical manifestations of mental illness in a person.

Doessel (1986) provides an economic analysis of the informational nature of the concept of diagnosis and Williams (2009) describes the underlying informational problems that have developed in mental health. Williams and Doessel (2010) present a conceptual economic analysis of the economic effects in mental health. The implication here involves acknowledging that the informational dimension with respect to diagnosis is vital to efficient resource allocation, as well as being vital for therapeutic purposes.

The use of need terminology here is not to ignore the perspective of the economic literature on need, which is that it is but one factor in consumer demand. The structural imbalance problem in mental health services under Medicare involves a mismatch in mental health services under insurance not found in other sectors of the economy. Note that the term 'need' with respect to health has several connotations. ${ }^{12}$ It is also not suggested here that service use and illness are completely misaligned in the mental health sector. Some people with no current symptoms are prone to relapse and require a 'maintenance' approach to therapy (Druss et al. 2007). Additionally, note that an optimal implementation of therapies at the current state of knowledge is implied in any study of structural imbalance (see Andrews et al. 2006).

The evidence for structural imbalance is located in the empirical results reported in a representative sample of the adult Australian population for the year 1997 drawn by the Australian Bureau of Statistics (ABS). Details of this ABS study (ABS 1998), such as coverage of mental health disorders, are provided in Appendix 1. Given that many disorders were not covered, the survey results underestimate the prevalence of mental illness. It is also recognised that mental health is beset with numerous controversies, as discussed briefly in Appendix 2 . The ABS study and, hence, our results set these controversies aside, as the ABS implemented the concepts, definitions and criteria embedded in ICD-10. ${ }^{13}$

Table 1 clearly indicates the structural imbalance that exists in the mental health sector. The columns indicate the number of Australian adults who have, and do not have, mental disorders. The rows show the number of people who

\footnotetext{
12 An economic classification of these connotations is available (Williams and Doessel 2011).

13 The 10th revision of the International Statistical Clasification of Diseases and Related Health Problems by the World Health Organization (WHO). The survey results implementing the DSM IV (the 1994 edition of the Diagnostic and Statistical Manual of Mental Disorders published by the American Psychiatric Association) definitions have been published separately in Andrews et al. (1999).
} 
consume, and do not consume, mental health services. ${ }^{14}$ As the table indicates, and not surprisingly, the largest group of Australian adults $(10,490,100)$ fall into the category of people who have no mental disorders and who do not consume mental health services: unmet non-need. The other unproblematic case consists of 905,600 people who have a mental disorder and are receiving treatment: met need. From a societal perspective the people in the other two cells are problematic: there are 1,466,500 people, 11 per cent of the population, who have mental disorders and do not receive any treatment. This is the often-described case of unmet need. But, as argued above, there is another problematic case, that of met non-need: there are 591,600 people, 4.4 per cent of the adult population, who are consuming mental health services despite having no mental illness. ${ }^{15}$

Table 1: The population-level relationships between mental disorders and the use of mental health resources (Australia, adults, 1997)

\begin{tabular}{|l|c|c|c|}
\hline & $\begin{array}{c}\text { Have a } \\
\text { mental disorder } \\
\text { Need' }\end{array}$ & $\begin{array}{c}\text { Do not have } \\
\text { a mental disorder } \\
\text { 'Non-need' }\end{array}$ & Totals by Row \\
\hline Consume mental health resources & $\begin{array}{c}905,600 \\
(6.7 \%) \\
\text { Met need }\end{array}$ & $\begin{array}{c}591,600 \\
(4.4 \%) \\
\text { Met non-need }\end{array}$ & $1,497,200$ \\
\hline $\begin{array}{l}\text { Do not consume mental health } \\
\text { resources }\end{array}$ & $\begin{array}{c}1,477,500 \\
(11.0 \%) \\
\text { Unmet need }\end{array}$ & $\begin{array}{c}10,490,100 \\
(77.9 \%)\end{array}$ & $11,967,600$ \\
\hline Totals by column & $\begin{array}{c}2,383,100 \\
(17.7 \%)\end{array}$ & $\begin{array}{c}11,081,700 \\
(82.2 \%)\end{array}$ & $\begin{array}{c}13,464,800 \\
(100.0 \%)\end{array}$ \\
\hline
\end{tabular}

Source: Derived from Australian Bureau of Statistics (1998) Tables 16 and 22.

Notes: i. The mental illnesses included in this epidemiological study are detailed in Appendix 1. ii. The mental health resources include the mental health services of GPs, psychiatrists, psychologists, nurses, pharmacists, ambulance officers etc. iii. The data employed here relate to Australian adults, i.e. persons 18 years and over, not the total Australian population.

An alternative way to depict structural imbalance is to use a Venn diagram, as in Figure 3. The total area of the diagram represents the adult Australian population. Consider now the two large circles: the larger circle represents 'mental health need'; that is, 17.7 per cent of the population with mental disorders in 1997. (This is the mental disorder prevalence rate determined by the ABS survey.)

14 The data in Table 1, being based on the ABS representative sample of the adult population, are subject to sampling error. But given the use of highly aggregated data in this paper, the standard errors of the estimates are relatively low, and the calculation of 95 per cent confidence intervals makes relatively little difference to the point estimates reported here. Details of the calculation of standard errors are published by the ABS (ABS 1998: 53-6). The relevant calculations are available from the authors on request.

15 It is important to note that there is a sex-related dimension of structural imbalance: the proportions relating to the met non-need and unmet need are not constant across men and women from the 1997 crosssectional data that we analysed: the problem of met non-need is considerably larger for women than for men. Details are in Doessel, Williams and Nolan (2008), Doessel, Williams and Whiteford (2010) and Williams and Doessel (2012). 
The smaller circle represents the share of the Australian population ( 11 per cent) who consumed mental health services. The first point to note is that the 'mental health need' circle is larger than the 'mental health services' circle: thus unmet need does exist and is indicated by the larger (11 per cent) crescent-shaped area of the mental health need circle. The other problematic case, met non-need (4.4 per cent of the population), is indicated by the smaller crescent-shaped area. To describe this empirical reality via a Venn diagram is to critique it, because implied in the Venn conceptualisation is a suggestion of the most desirable state. This (normative) state occurs when the two circles are perfectly aligned; that is, a state where there is no unmet need and no met non-need.

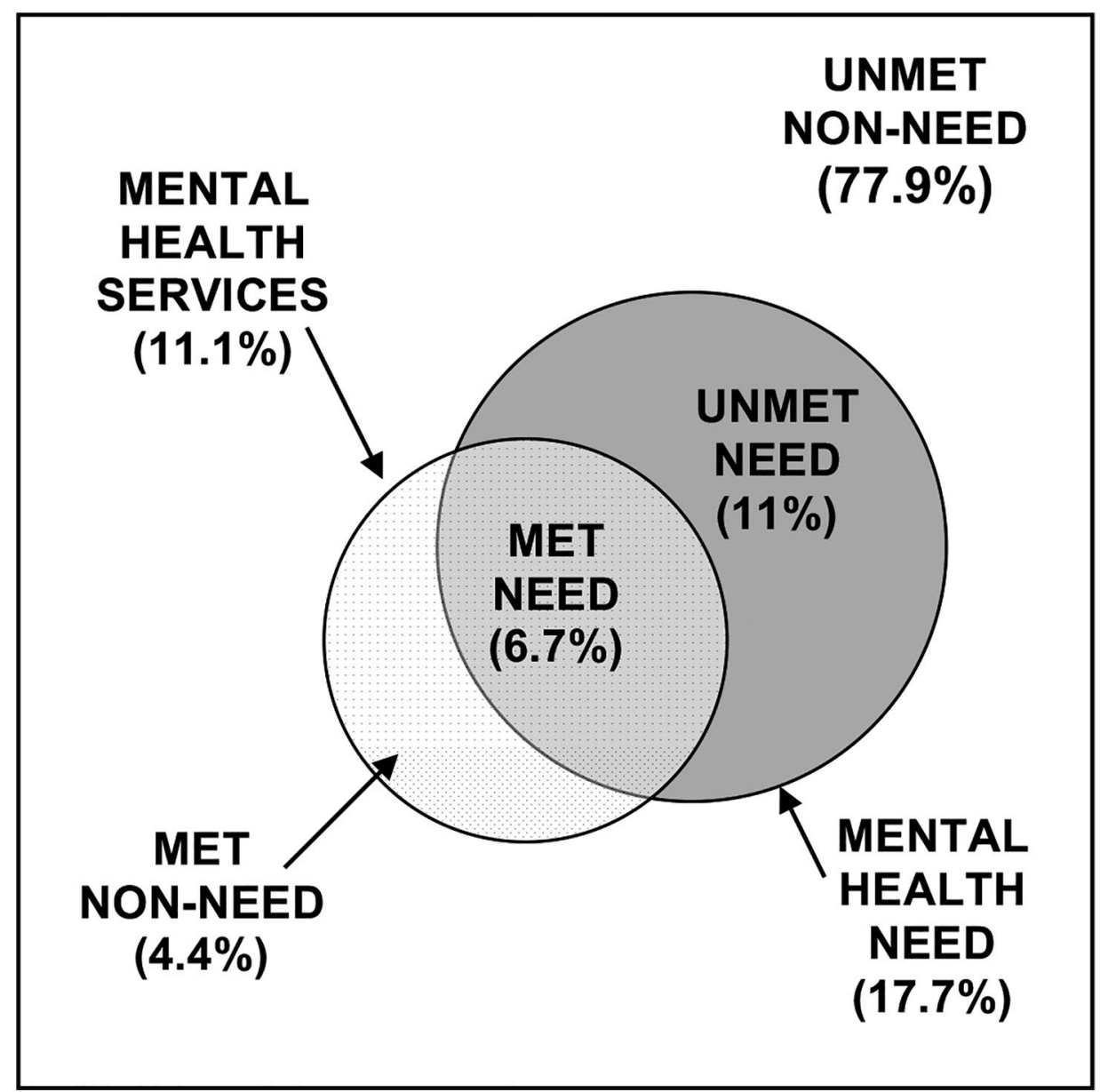

Figure 3: Structural imbalance in Australian mental health care, 1997 Source: Doessel, Williams and Nolan (2008).

Note: The figure refers to Australia's adult population. 
The structural imbalance phenomenon can be also understood by reference to the perfect/imperfect correspondence concepts in fiscal federalism: this framework, building on arguments in Musgrave (1959, 1961), Tiebout (1961) and Oates (1968), is concerned with assigning allocative functions, in the sense of Musgrave's (1959) 'Allocation Branch', to different levels of government, and matching revenue bases to those levels of government. A much-quoted expression from Oates (1972: 34-5) is 'perfect correspondence', which exists when 'a jurisdiction [whose taxpayers fund the public good] includes precisely the set of individuals who consume the [public] good'. The case of perfect correspondence (an extreme case) can be depicted in a Venn diagram in which the set of taxpayers coincides exactly with the set of public-good consumers or beneficiaries. The other polar case, perfect non-correspondence, can also be depicted in a Venn diagram, with the set of taxpayers being completely separate from the set of public-good consumers. It is likely that any particular governmental structure will not be at either of these polar cases: empirical reality will be at some intermediate case. ${ }^{16}$

Figures 4(a) and 4(b) illustrate the two possible polar cases of perfect correspondence and perfect non-correspondence of mental illness and the consumption of mental health services. It is clear that Australia's empirical reality in Figure 3 is intermediate between these two extreme cases. This approach is relevant not just for the issue under study here: it provides an important framework to evaluate any reform in the mental health sector. Efficacy of any mental health reform can be measured by decreases in the quantities of the two problematic phenomena of met non-need and unmet need.

Quarterly time-series data, from 1997(1) to 2008(4), obtained from the complete enumeration of all Medicare Benefits claims for Australia, have also been analysed (Doessel and Williams 2011). The analysis of time-series clinical data (from Medicare) provides additional support for the existence of the phenomenon of met non-need. Thus, the phenomenon exists in both crosssection and time-series data. ${ }^{17}$

16 See Hunter (1974) for an early derivation of an index of such fiscal imbalance, or non-correspondence of government expenditure and taxation receipts. His paper concludes with empirical measures of the noncorrespondence for the different fiscal systems of various countries.

17 Space considerations preclude a more detailed exposition here. 
(a)

PERFECT CORRESPONDENCE

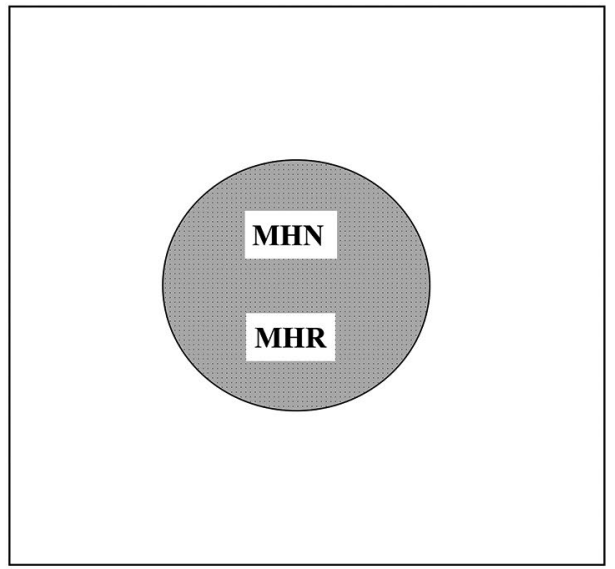

Notes: MHN: Persons with mental health need MHR: Persons consuming mental resources (b)

PERFECT NON-CORRESPONDENCE
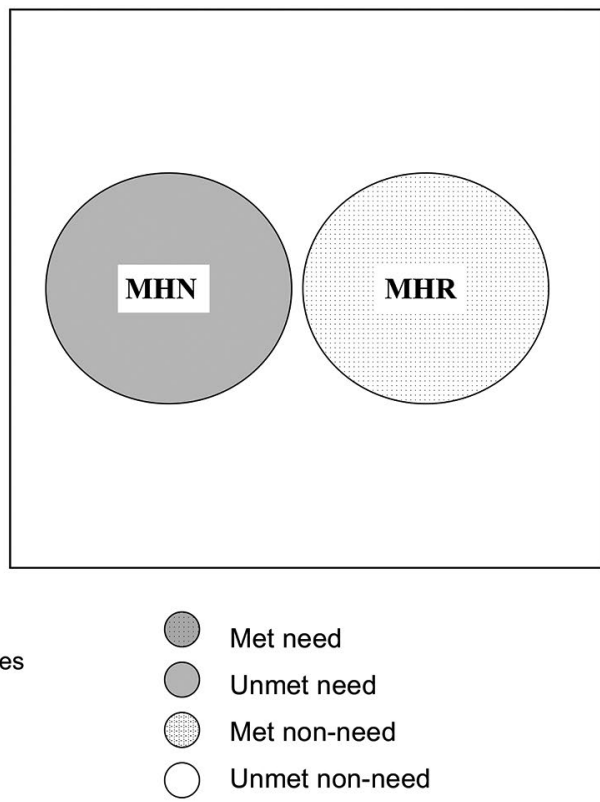

Figure 4: Structural imbalance in Australian mental health care as 'imperfect balance'

Before turning to a policy discussion, some further points are relevant.

Note that structural imbalance, or the service non-correspondence problem, should not be regarded as unique to Australia. This phenomenon has also been documented in the United States (US Department of Health and Human Services 1999), Canada (Lin et al. 1996), New Zealand (Oakley Browne and Wells 2006) and most recently across all the countries surveyed in the WHO Mental Health Surveys (Demyttenaere et al. 2004). Bruffaerts et al. (2015) provide meta-analysis from the WHO Mental Health Surveys of adults conducted variously in 23 countries, and separate studies also report results for each of the 23 countries surveyed.

Note also that amidst extensive results reported in the WHO Surveys, there is a finding that 15.9 per cent of the surveyed respondents are in treatment, although having neither a mental disorder nor evidence of serious problems that would require treatment. This finding is glossed over by a clinical or health service research mind-set. Psychiatrists and psychologists invariably focus empirical work for policy discussion on unmet need. They are not interested in quantifying met non-need, even if researchers from these disciplines were to recognise its existence. This is unsurprising. Our focus is on rectifying this very 
important oversight, as there are economic implications. It needs to be borne in mind, too, that the Australian figure for met non-need, 4.4 per cent of the adult population, may be a sizeable underestimate. ${ }^{18}$

While a great deal more epidemiological and clinical work on this phenomenon is needed to refine the quality of data and results, the evidence is accumulating and the underlying economic phenomenon, though vital, is still unacknowledged.

\section{A policy response}

We suggest that the structural imbalance, or imperfect correspondence, problem can be ameliorated. We believe that an appropriate policy response is that when mental health services are sought under Medicare, a precondition should be positive results on the relevant diagnostic tests from the large range of psychological tests that is available (Beck's Depression Inventory, Personality Assessment Inventory, the Neuropsychiatric Inventory, behavioural disturbances tests in dementia patients, and so on). There is an abundance of such tests, devised generally by psychologists.

Separately itemised diagnostic items about an individual's mental health status can be included in the Medicare Benefits Schedule for mental health conditions, and can be made a prerequisite for receiving Medicare subsidies. Our proposal is that new items (with appropriate codes and fees) be created and that positive results from such relevant tests be made a precondition for receiving any specialist therapeutic mental health services.

This proposal is not path-breaking: it amounts to an extension of an existing precondition, as a part of the Medicare Benefit Schedule for psychiatrist services. An appropriate score on the Global Assessment of Functioning (GAF) Scale is already a precondition for receiving some services (Doessel et al. 2007). There are many validated instruments available to diagnose mental disorders; the problem is that they are not administered. Elsewhere in the health sector, diagnostic testing is the norm prior to claims on Medicare for treatment services.

Structural imbalance is a fixable policy problem. It has been said of mental health economics as a sub-field (Frank, Glazer and McGuire 2000: 895), that it is:

like health economics only more so: uncertainty and variations in treatments are greater; the assumption of patient self-interested behaviour is more dubious; response to financial incentives such as insurance is exacerbated; the social consequences and external costs of illness are more formidable.

18 The ABS survey data above have been criticised for their possibly inadequate account of the type of service provision that is relevant for people with one-off traumatic events, such as terrorist attacks. Table 29.3 in Bruffaerts et al. (2015) takes account of this class of service user. 
Despite some formidable hurdles to economic analysis of mental health services, a feasible step forward is available, as outlined in this paper.

\section{Conclusion}

Our concern is to address the information problem associated with inadequate diagnostic testing in mental health. This inadequacy underlies the structural imbalance defined and measured in our previous articles. Policy that addresses the information problem involves the creation of new diagnostic items, or codes, in the Medicare Benefits Schedule for specialist psychiatric services and specialist psychology services in much the same way as itemised diagnostic services are currently used in physical medical practice. Our policy proposal for Australia's mental health sector is analogous to Medicare financing of information, or 'the diagnosis', which has an integral role in the production processes of surgery, gastroenterology, ophthalmology, orthopaedics, and so on. A reform emphasis on the informational problem has the effect of reallocating met non-need expenditures to other categories within the mental health sector. Our objective here is to cure structural imbalance by reallocating scarce mental health services to those in need, and this paper provides yet more evidence on the means of achieving the objective. The non-existence of diagnostic tests for mental health conditions is a problem in the structure of the Medicare Benefits Schedule.

The case that we argue here arises from a refrain about the problems of mental health systems sung repeatedly, with a theme and repetitions. This refrain has two themes: insufficient funding and unmet need. Unmet need is not a trite neologism: it is a well-embedded concept in the psychiatric literature, a concept devised and advocated by clinical psychiatrists, and a synonym for untreated mental illness. But whereas emphasis is placed on this unmet need, no one puts equivalent emphasis on the problem of met non-need. It is clear to those outside the clinical 'inner circle' that providing mental health services to people who have no mental disorders involves a straightforward waste of resources. Having elucidated the concept of structural imbalance, as well as providing further evidence about it and suggesting a policy response, we conclude that this waste can, and should, be brought to an end, and those resources should be devoted to the problem of unmet need. 


\section{Appendix 1: Sources and measures}

This paper is based on Mental health and wellbeing: Profile of adults, Australia, 1997 (ABS 1998), a representative sample survey of the non-institutionalised Australian population aged 18-65 and over. The sample does not include people in institutions (prisons, hospitals, nursing homes, refuges, hostels, boarding houses) or, of course, the homeless.

The ABS study is but one of three studies of mental disorders undertaken in 1997. ${ }^{19}$ The other two deal with children and adolescents (aged 3-17) and people subject to numerous low-prevalence disorders. Data from these two studies cannot be aggregated with those from the ABS study for various reasons of noncomparability. Thus the data employed in this study underestimate the extent of mental disorder (as defined).

This study has been reported using the two systems of classifying mental disorders; that is, the International Classification of Diseases, Version 10 (ICD-10) and the Diagnostic and Statistical Manual Revision IV (DSM IV). However, in our discussion, we refer only to ICD codes. The 40 individual components in the ABS study, and their ICD codes, are as follows:

\section{Substance use disorders}

F10.1 Harmful use - alcohol

F11.1 Harmful use - opioids

F12.1 Harmful use - cannabinoids

F13.1 Harmful use - sedatives or hypnotics

F15.1 Harmful use - stimulants

F10.2 Dependence syndrome - alcohol

F11.2 Dependence syndrome - opioids

F12.3 Dependence syndrome - cannabinoids

F13.2 Dependence syndrome - sedatives or hypnotics

F15.2 Dependence syndrome - stimulants

19 Note the term 'Wellbeing' in the ABS survey title. The term does not appear in the Glossary, although 'Mental disorder' and 'Mental health problem' do (ABS 1999: 79-83). The objective of the survey was to measure illness, not wellness. The Australian Statistician was quite clear: the purpose was to collect 'information on the prevalence of selected mental disorders, associated disability and the use of health services for Australian adults' (p. v). Thus, the use of the term is best understood as window-dressing. During the 1990s, developments were under way in (mainly) psychology and, later, economics that are relevant to wellness, but there is no mention of, even allusion to, these developments in the ABS publications, or in Department of Health and Aged Care publications. 


\section{Affective disorders}

F30.0 Hypomania

F30.1 Mania without psychotic symptoms

F30.2 Mania with psychotic symptoms

F31 Bipolar affective disorder

F32.0 Mild depressive disorder

F32.1 Moderate depressive episode

F32.2 Severe depressive episode without psychotic symptoms

F32.00 Mild depressive episode without somatic syndrome

F32.01 Mild depressive episode with somatic syndrome

F32.10 Moderate depressive episode without somatic syndrome

F32.11 Moderate depressive episode with somatic episode

F33.00 Recurrent depressive disorder, mild without somatic syndrome

F33.01 Recurrent depressive disorder, mild with somatic syndrome

F33.10 Recurrent depressive disorder, moderate without somatic syndrome

F33.11 Recurrent depressive disorder, moderate with somatic syndrome

F33.2 Recurrent depressive disorder, severe without psychotic symptoms

F34.1 Dysthymia

\section{Anxiety disorders}

F40.0 Agoraphobia

F40.00 Agoraphobia without panic disorder

F40.01 Agoraphobia with panic disorder

F40.1 Social phobia

F41.0 Panic disorder

F41.00 Panic disorder - moderate

F41.01 Panic disorder - severe

F41.1 Generalised anxiety disorder

F42.0 Obsessive compulsive disorder - predominantly obsessive thoughts or ruminations

F42.1 Obsessive compulsive disorder - predominantly compulsive acts

F42.2 Obsessive compulsive disorder - mixed obsessional thoughts and acts

F43.1 Post-traumatic stress disorder

\section{Neurasthenia}

F48.0 Neurasthenia

Both the ICD and DSM classification systems produce the same (total) number of people with these mental disorders. 
Among the conditions not included are:

- schizophrenia, psychopathy, sociopathy and hypochondria, as they are lowprevalence disorders

- dementia, as many people with this disorder are located in nursing homes, which are not included in the ABS sampling frame. While some people with dementia will be in private dwellings, to include them would produce a quite inaccurate prevalence rate for dementia

- some well-known personality disorders (e.g. Narcissistic Personality Disorder)

- autism, as this relates to persons under 18 years of age

- deficiency of 'Wellness'. ${ }^{20}$

\section{Appendix 2: Mental health and its controversies}

Controversy seems to attach itself to various mental illnesses and conditions. ${ }^{21}$ There is also the question of when depression is illness and when it is not. Though such controversies are not covered in this paper, we are well aware that they exist. The economic connotations implicit in a clinical-sounding question like 'When is depression illness ...?' are explicated in Williams (2009). Also, our book (Williams and Doessel 2001: 133-5) began to address such problems, employing Lancaster's characteristics theory to the outputs of mental health services. The concepts that we applied at that time were socially unacceptable preferences, impaired preference capacity, and imperfect information. That book was written nearly two decades ago and our subsequent work has

\footnotetext{
20 This term is associated with the psychologist Martin Seligman, who tried to bring about a change in emphasis in psychology: instead of psychology concentrating on illness, Seligman wanted psychologists to analyse the determinants of happiness, as his book titles suggest: Learned optimism: How to change your mind and your life (1991); Authentic happiness: Using the new psychology to realise your potential for lasting fulfilment (2011); and Flourish: A visionary new understanding of happiness and well-being (2011). Seligman is not arguing that his happiness work is a substitute for 'dominant' psychology, but a complement. Contemporaneous with Seligman, papers on utility and the psychology of utility began to appear (for example, those by Thaler, Fredriksson and Snell, all of whom co-authored with Daniel Kahneman). This work culminated in a major volume of work on hedonic psychology published in 1999 (Kahneman et al. 1999), which intersects with the economic literature on happiness. These two developments at the forefront of psychology (and the interconnections with economics) were taking place at much the same time as planning was under way for the tripartite surveys of mental illness in Australia. Neither these developments in positive psychology nor those in hedonic psychology have had any effect on the Department of Health and Aged Care-funded prevalence studies of mental illness. Those mental illness studies were the 'property' of psychiatrists.

21 There is, for instance, the 'autism epidemic', repetitive strain injury as an occupational health and safety issue involving industrial compensation claims, the various issues surrounding obsessive-compulsive disorder (OCD) as an illness contrasted with 'being meticulous' as an occupational character trait and a skill required for various fields of work. Space limitations preclude a detailed discussion here.
} 
had an empirical basis. In the interim, too, many more controversies have emerged, which led, in part, to our broader economic analysis (Williams and Doessel 2010).

Economic issues abound in all these controversies. There is imperfect information with respect to many mental illnesses, and there is also producer ignorance and producer uncertainty. Impaired preference capacity exists in some diagnoses of mental illness, such as dementia: aged-care funding involves major economic analysis. There is also the case of autism and its carers, which suggests that financial benefits can be an inducement that results in an increase of prevalence. ${ }^{22}$ Also, there is a phenomenon that can be referred to as pharmacologically induced mental illness, and/or iatrogenic illness. ${ }^{23}$

Consumer ignorance with respect to mental illness now seems to be increasing. Misperceptions have increased in the last decade or so. For instance, the very loose use of the term 'depression' is now widespread. Various other words with strict clinical meanings - 'delusion' (Richard Dawkins' book The God Delusion is not about mental illness but the author's embrace of angry atheism), 'addiction', 'OCD' and so on - are now in everyday use, with muddying and muddling effect. 'Mental health issue' is a neologism but tends to be nebulous. The lack of precision of this term makes its use particularly unhelpful in workplaces and in assessing student performance in schools and universities.

We have not broached these issues here. The very purpose of our study is to abstract from each controversy. By not referring to the individual instances and how each could be remedied, this paper can be thought as more like weighing up the second-best, as opposed to the best, solution (Lipsey and Lancaster 1956; Mishan 1962).

\section{References}

Abel-Smith, B. 1963, Paying for health services: A study of the costs and sources of finance in six countries, World Health Organization, Geneva.

Andrews, J.G., Hall, W.D., Teesson, M. and Henderson, S. 1999, The mental health of Australians, Mental Health Branch, Commonwealth Department of Health, Canberra.

22 Funding is also now available for carers of people with mental illness and for various mental issues. De Waal (2015) has an examination of increased prevalence induced by financial benefits.

23 Yolande Lucire's web page, drlucire.com/attention-health-ministers.html\#_ednref, is relevant to some of the arguments summarised here. 
Andrews, J.G. and the Tolkien II Team 2006, Tolkien II. A needs based, costed stepped-care model for mental health services, World Health Organization Collaborating Centre for Classifications in Mental Health, Sydney.

Apte, U.M. and Nath, H.K. 2007, 'Size, structure and growth of the US information economy' in A.M. Apte and U.S. Karmarkar (eds), Managing in the information economy: Current research issues, Springer, New York: 1-28.

Australian Bureau of Statistics 1998, Mental health and wellbeing: Profile of adults, Cat. No. 4326.0, ABS, Canberra.

- 1999, National survey of mental health and wellbeing of adult users' guide, Cat. No. 4327.0, ABS, Canberra.

Australian Institute of Health and Welfare (AIHW) 2015, Mental Health Services in Australia, AIHW, Canberra.

— 2016, 25 Years of Health Expenditure in Australia 1989-90 to 2013-14, AIHW, Canberra.

Bruffaerts, R., Posada-Villa, J., Al-Hamzawi, A. et al. 2015, 'Proportion of Patients without Mental Disorders being Treated in Mental Health Services Worldwide', The British Journal of Psychiatry: the Journal of Mental Science 206(2): 101-9.

De Waal, A. 2015, The Real Politics of the Horn of Africa: Money, War and the Business of Power, Polity Press, Cambridge, UK.

Demyttenaere, K., Bruffaerts, R., Posada-Villa, J. et al. 2004, 'Prevalence, Severity, and Unmet Need for Treatment of Mental Disorders in the World Health Organization World Mental Health Surveys', JAMA 291(21): 2581-90.

Doessel, D.P. 1986, 'Medical Diagnosis as a Problem in the Economics of Information', Information Economics and Policy 2(1): 49-68.

- 2009, 'A Historical Perspective on Mental Health Services in Australia: 1883-84 to 2003-04', Australian Economic History Review 49(2): 173-97.

Doessel, D.P., Scherer, R.W., Chant, D.C. and Whiteford, H. 2007, 'Financial Incentives and Psychiatric Services in Australia: An Empirical Analysis of Three Policy Changes', Health Economics, Policy and Law 2: 7-22.

Doessel, D.P., Williams, Ruth F.G. and Whiteford, H. 2010, 'Structural Imbalance and Resource Shortage in Mental Health: Australian Results', Journal of Mental Health Policy and Economics 13(1): 3-12. 
Doessel, D.P. and Williams, Ruth F.G. 2011, ‘Resource misallocation in Australia's mental health sector under Medicare: evidence from time-series data', Economic Papers 30(2): 253-64.

Doessel, D.P., Williams, Ruth F.G. and Nolan, P. 2008, 'A Central Dilemma in the Mental Health Sector: Structural Imbalance', Clinical Psychologist 12(2): 57-66.

Druss, B.G., Wang, P.S., Sampson, N.A., Olfson, M., Pincus, H.A., Wells, K.B. and Kessler, R.C. 2007, 'Understanding Mental Health Treatment in Persons without Mental Diagnoses: Results from the National Comorbidity Survey Replication', Archives of General Psychiatry 64(10): 1,196-203.

Frank, R.C., J. Glazer and T.G McGuire 2000, 'Measuring adverse selection in managed health care', Journal of Health Economics 19(6): 829-854.

Hickie, I. 2016, 'PM can Help to Transform our Mental Health Care', The Australian, 15 July.

Hosking, Jenny 2010, 'Much More Money is Needed for Strained Mental Health Sector', The Sydney Morning Herald, 22 June.

Human Rights and Equal Opportunity Commission (HREOC) 1993, Human Rights and Mental Illness - report of the National Inquiry into the Human Rights of People with Mental Illness, AGPS, Canberra.

Hunter, J.S.H. 1974, 'Vertical Intergovernmental Financial Imbalance: A Framework for Evaluation', Finanzarchiv 2(3): 281-92.

Kahneman, D., Diener, E. and Schwarz, N. (eds) 1999, Well-being: The foundations of hedonic psychology, Russell Sage Foundation, New York.

Lin, E., Goering, P., Offord, D.R., Campbell D. and Boyle M.H. 1996, 'The Use of Mental Health Services in Ontario: Epidemiological Findings', Canadian Journal of Psychology 41(12): 572-7.

Lipsey, R.G. and Lancaster, K. 1956, 'The General Theory of Second Best', Review of Economic Studies 24(1): 11-32.

Machlup, F. 1962, The Production and Distribution of Knowledge in the United States, Princeton University Press, Princeton.

McGorry, P.D., Edwards, J., Mihalopoulos, C., Harrigan, S.M. and Jackson, H.J. 1996, 'EPPIC: An Evolving System of Early Detection and Optimal Management', Schizophrenia Bulletin 22(2): 305-26.

Medicare Australia (various), Medicare Benefits Schedule, AGPS, Canberra. 
Mental Health Australia 2015, 'The Time for Talk is Over - it's Time for Action in Mental Health', Media release, 15 July. Available at: mhaustralia.org/ media-releases/time-talk-over-its-time-action-mental-health.

Mental Health Council of Australia 2005, Not for service: Experiences of injustice and despair in mental health care in Australia, Mental Health Council of Australia, Canberra.

Mishan, E.J. 1962, 'Second Thoughts on Second Best', Oxford Economic Papers New Series 14(3): 205-17.

Musgrave, R.A. 1959, The theory of public finance, McGraw Hill, New York.

— 1961, 'Approaches to a Fiscal Theory of Political Federalism' in UniversitiesNBER, Public finance: needs, sources and utilization, Princeton University Press, Princeton, pp. 97-133.

National Mental Health Commission 2015, Contributing lives, thriving communities: the national review of mental health programmes and services, NMHC, Sydney.

Oakley Browne, M.A. and Wells, J.E. 2006, 'Health Services' in M.A. Oakley Browne et al. (eds), Te Rau Hinengaro: the New Zealand mental health survey, Ministry of Health, Wellington, NZ.

Oates, W.E. 1968, 'The Theory of Public Finance in a Federal System', Canadian Journal of Economics/Revue Canadienne d'Economique 1(1): 37-54.

— 1972, Fiscal Federalism, Harcourt Brace Jovanovich, New York.

Opit, L.J. and Gadiel, D.L. 1982, “The Demand for Private Psychiatric Services in a Health Insured Population", Community Health Studies VI(2): 93-8.

Porat, M. 1977, The information economy, US Department of Commerce, Washington, DC.

Tiebout, C.M. 1961, 'An Economic Theory of Decentralization', in UniversitiesNBER (1961) Public finance: needs, sources and utilization, Princeton University Press, Princeton, pp. 79-96.

US Department of Health and Human Services 1999, Mental health: a report of the surgeon general - executive summary. US Department of Health \& Human Services, Substance Abuse and Mental Health Services Administration, Center for Mental Health Services, National Institutes of Health, National Institute of Mental Health, Rockville. Available at: surgeongeneral.gov/ library/mentalhealth/home.html. 
Whiteford, H. 1994, 'The Australian Health Ministers' Advisory Council (AHMAC) and the National Mental Health Reforms', Australian Psychiatry 2(3):101-4.

Whiteford, H. and Buckingham, W. 2005, 'The Process of Transforming Mental Health Services in Australia', International Journal of Mental Health 34(1): 55-71.

Williams, Ruth F.G. 2009, ‘Review Article: Everyday Sorrows are not Mental Disorders: the Clash between Psychiatry and Western Cultural Habits', Prometheus 27(1): 47-70.

Williams, Ruth F.G. and Doessel, D.P. 2001, The Economics of Mental Health Care: Industry, Government and Community issues, Ashgate, Aldershot.

- 2010, 'Psychiatry Interacts with Contemporary Western Views: the DSM-III Innovation and its Adverse Effects', Prometheus 28(3): 245-66.

_ 2011, An Economic Classification of "Health Need"', International Journal of Social Economics 38(3): 291-309.

— 2012, “Mental Health Services are Different": Economic and Policy Effects' in L'Abate, L. (ed.), Mental Illness, In-Tech. 
This text is taken from Agenda, Volume 23 - Number 1, 2016, edited by William Coleman, published 2016 by ANU Press, The Australian National University, Canberra, Australia. 